\title{
Capillary blood collecting system for glucose determination
}

\author{
PHILIP G. WILES \\ B.Sc., M.R.C.P.
}

\author{
PETER J. WATKINS \\ M.D., F.R.C.P.
}

Diabetic Department, King's College Hospital, London SE5 9RS

\begin{abstract}
Summary
A method of self collection of blood is described for use by diabetic patients unable, or unwilling, to determine their own blood glucose, and for when accurate results are required for research purposes.

A commercially available 'flask' capillary blood collecting system can be used to collect $50 \mu \mathrm{l}$ blood for glucose determination on a Yellow Springs analyser. The results are accurate when compared to Auto Analyzer $(r=0.988)$ and are unaffected by storage at $4^{\circ} \mathrm{C}$ for up to 28 days $(r=0.998)$. This system is easily available, readily accepted by patients, and the method consumes minimal laboratory time.
\end{abstract}

KEY WORDS: diabetes mellitus, blood glucose, capillary collection system.

\section{Introduction}

With the increasing awareness of the importance of good diabetic control has come the development of home blood glucose monitoring. Present systems generally utilise reagent strips, with or without a colorimeter, which are read and recorded by the patients themselves. This has the advantage of allowing day-to-day adjustment of insulin dosage, but does depend upon the reliability of the individual and, in our experience, accuracy of strip testing varies considerably among patients.

Other methods of home capillary blood collection have been assessed. In particular, the use of filterpaper blood spots (Wakelin et al., 1978), a fluoride vacuum bottle (Howe-Davies et al., 1978), or a $5 \mu \mathrm{l}$ capillary system (Williams, Davies and Childs, 1981) have been described. These methods require laborious assay procedures, complicated vessel preparation or difficult collection techniques. The $5 \mu$ l capillary system has the advantage of accuracy and ease of collection as such a small volume is required. However, the methods of kit-preparation and sample assay consume considerable laboratory time.

We should like to report on our assessment of a commercially available 'flask' capillary blood collect- ing system suitable for use in any diabetic clinic and $\frac{0}{3}$ which we now use regularly.

\section{Methods}

Using a Monolet Lancet or Autolet* system, the thumb, finger pulp or earlobe is punctured and blood drawn by capillary action into a 'flask' collecting vessel $\dagger$. When approximately one third full $(100 \mu l), \vec{z}$ the caps are placed on the vessel (narrow end first) which is shaken to facilitate mixture with sodium fluoride. It is then placed in the protective outer $\mathscr{C}_{\infty}$ sleeve in which it can be safely transported or stored if required (Fig. 1).

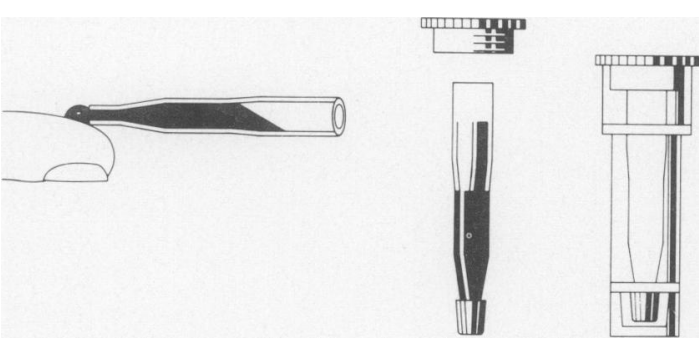

FIG. 1. System for capillary blood collection.

The Sarstedt tube will hold up to $300 \mu$ lof blood and blood glucose can be determined by any method $\mathrm{N}$ requiring 100-200 $\mu \mathrm{l}$ of blood or less. We use a N Yellow Springs analyser (YS1 model 23AM). The N needle of a 'syringepet' can be inserted into the lumen of the vessel to withdraw, accurately, $25 \mu \mathrm{l}<$ aliquots for injection into the analyser chamber. Thus, accurate glucose determination can be made

*Owen Mumford Ltd., Woodstock, Oxford.

+Walter Sarstedt (UK) Ltd (Cat. No. 16/446), Leicester LE3 IUQ. 


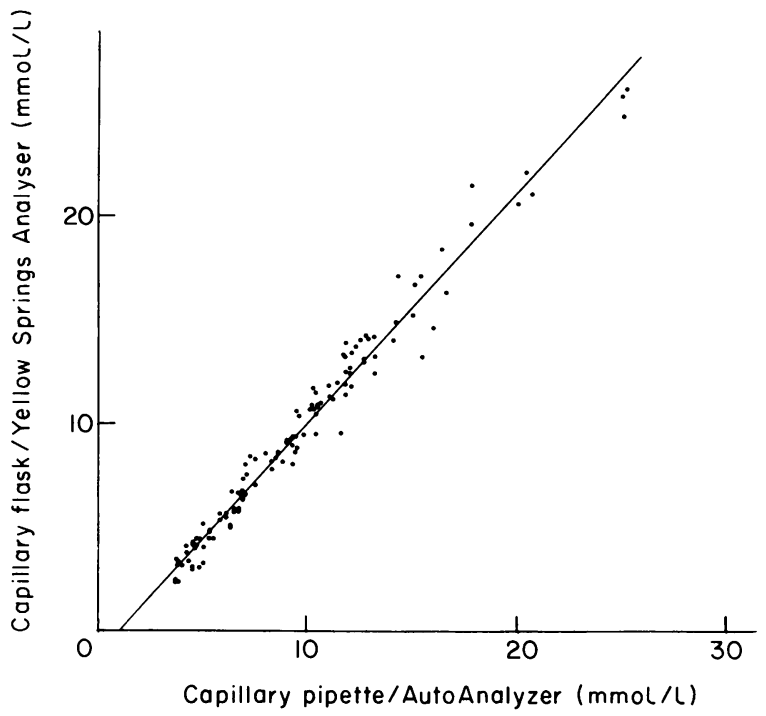

FIG. 2. Correlation of blood glucose results on paired samples $(n=120)$ collected simultaneously into $0.1 \mathrm{ml}$ capillary pipettes (for Auto Analyzer) and Sarstedt tubes (for Yellow Springs Analyser). $r=0.988, \mathrm{y}=1.0980 \mathrm{x}-0.9998$.

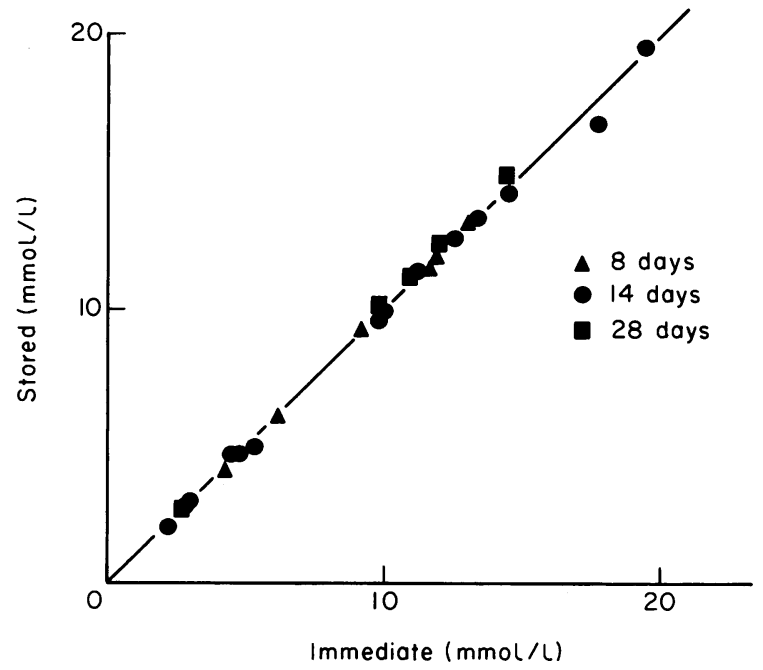

FIG. 3. Correlation of blood glucose results on paired samples $(n=26)$ collected into Sarstedt tubes, one analysed immediately, the other stored at $4^{\circ} \mathrm{C}$ for 8 days $(n=7), 14$ days $(n=14)$, or 28 days $(n=5) r=0.998, \mathrm{y}=1.0035 \mathrm{x}-0.0256$.

on only $50 \mu \mathrm{l}$ of blood. A result can be obtained from a sample of 25-30 $\mu \mathrm{l}$ blood, but since the manufacturers recommend flushing the syringepet with blood before drawing up for analysis, results are thus less accurate. Once calibrated ( $3 \mathrm{~min})$, the machine takes approximately $75 \mathrm{~s}$ per sample.

Blood glucose determinations were made on 120 patients in the clinic from whom capillary samples were taken directly and analysed by Auto Analyzer (ferricyanide method) and compared with the result on capillary specimens taken into Sarstedt tubes and analysed on the Yellow Springs analyser (glucose oxidase method).

A further 26 pairs of samples were collected into two Sarstedt tubes, one being analysed immediately, the other stored for 8 days $(n=7), 14$ days $(n=14)$ or 28 days $(n=5)$ at $4^{\circ} \mathrm{C}$ before analysis.

\section{Results}

A very close correlation was found between the results obtained by the 2 methods $(r=0.988)$ within the range $2-30 \mathrm{mmol} /$ litre (Fig. 2). For values below $10 \mathrm{mmol} /$ litre, 12 of 68 paired glucose determinations differed by more than $1 \mathrm{mmol} /$ litre, none by more than $2 \mathrm{mmol} / \mathrm{litre}$; for values above $10 \mathrm{mmol} /$ litre, 16 of 52 paired estimations differed by more than $1 \mathrm{mmol} /$ litre, only 2 by more than $2 \mathrm{mmol} /$ litre. Similarly, there was a good correlation between the samples before and after storage $(r=0.998$, see Fig. 3 ), with no paired estimates differing by more than 1 mmol/litre, demonstrating that samples could safely be stored at $4^{\circ} \mathrm{C}$ for up to 28 days before transport to the clinic.

Twenty-three out-patients each provided 8 profiles of 7 samples in $24 \mathrm{hr}$ at 2-weekly intervals. Each patient was carefully instructed, including a demonstration by the investigator and a practice by the patient, in a session lasting 20 minutes. Most patients then required a further day's practice at home to master the technique. All but two then found collection easy, producing the required amount of blood from a single Monolet finger-prick.

\section{Discussion}

This procedure is thus relatively simple to use, commercially available and, after careful training, readily acceptable to patients. Reliable blood glucose results are obtained. Samples taken at home by the patient, or on the ward by nurses, can be stored and analysed with great accuracy at any time thereafter. This technique is therefore an ideal research tool for out-patient clinical trials whereby all samples can be assayed by one technician or doctor. We have found it helpful for improving control of diabetes in patients who do not seem capable or willing to accept responsibility for monitoring their own control. Those unable to provide full profiles can bring fewer samples to the clinic for analysis, providing valuable additions to the single clinic blood glucose on which management is usually based. For those patients who do undertake home monitoring using reagent strips, this method may be useful to assess the accuracy of their own measurements, and it can be used to check 
the results of those suspected of manipulating their readings. In the ward, this technique has become a useful alternative to venous sampling for emergency or routine blood glucose determinations by nursing staff and thus reduces errors caused by reliance on erroneous interpretations of reagent strip results in inexperienced hands.

\section{Acknowledgments}

Dr Wiles is supported by Eli Lilly \& Co.

\section{References}

Howe-Davies, S., Holman, R.R., Phill.ip, M. \& Turner, R.C. (1978) Home blood sampling for plasma glucose assay in control of diabetes. British Medical Journal, 2, 596 .

WAKELIN, K., Goldie, D.J., HARTOG, M., \& Robinson, A.P. (1978) Measurement of capillary blood glucose in filter paper spots: an aid to the assessment of diabetic control. British Medical Journal, $2,468$.

Williams, C.P., Davies, G.K. \& ChILD, D.F. (1981) A novel fivemicrolitre capillary system for home glucose monitoring. Annals of Clinical Biochemistry, 18, 304.

(Accepted 18 November 1982) 